\title{
MNDO and DFT Computational Study on the Mechanism of the Oxidation of 1,2-Diphenylhydrazine by Iodine
}

\author{
Gideon A. Shallangwa, Adamu Uzairu, Victor O. Ajibola, and Hamza Abba \\ Department of Chemistry, Ahmadu Bello University, Zaria 810006, Nigeria
}

Correspondence should be addressed to Gideon A. Shallangwa; gashallangwa@gmail.com

Received 3 February 2014; Accepted 2 March 2014; Published 27 March 2014

Academic Editors: W. B. Davis, H. Luo, H. Pal, and E. B. Starikov

Copyright ( 2014 Gideon A. Shallangwa et al. This is an open access article distributed under the Creative Commons Attribution License, which permits unrestricted use, distribution, and reproduction in any medium, provided the original work is properly cited.

\begin{abstract}
The reaction mechanisms of the oxidation of 1,2-diphenylhydrazine by iodine have been examined using semiempirical and density functional theory methods, the oxidation proceeded via two independent pathways that can be separately monitored. One pathway involved the chain multistep mechanism. The other pathway occurred via a one-step mechanism in which a "cyclic" activated complex was formed which on disproportionation gave the products. The one-step "cyclic" activated complex mechanism proceeds more rapidly than the chain multistep mechanism. The results were explained by analyses based on computational energetics of the optimised reactants, intermediates, transition states, and products of the reaction of iodine with 1,2-diphenylhydrazine.
\end{abstract}

\section{Introduction}

1,2-Diphenylhydrazine is used as an antisludging additive to motor oil, a desuckering agent for tobacco plants, a reductant in the reclamation of rubber, a component of experimental organometallic polymers, an ingredient in photochromic resin compositions, and a component in polymerization reactions $[1,2]$. It is also used in the manufacture of hydrogen peroxide $[1,2]$. Some 1,2-diphenylhydrazine derivatives are used as flame-retardant agents [3]. Several aryl hydrazine interactions in small molecule complexes have been studied to see how they might react with iron and other substances [4]. Some of the studies found that a $3 \mathrm{mM}$ solution of benzene completely disproportionate 6 equivalents of 1,2diphenylhydrazine into aniline and azobenzene. The effort of study to shift the chemistry in a different direction was only partially successful. Several others [5-9] have also reported that the reactions of 1,2-diphenylhydrazine and its derivatives were $\mathrm{pH}$ dependent and would yield different products depending on the $\mathrm{PH}$ of the reaction medium. These studies [4-9] concluded that 1,2-diphenylhydrazine and its derivatives enjoy complicated chemistries that include structural rearrangement and disproportionation and that their interactions with metal ions or inorganic substances are complex and incompletely understood. Although 1,2diphenylhydrazine is known to be oxidized readily by many oxidants [10-17], only in a few other cases have the reaction mechanisms been examined, especially its reaction mechanisms with iodine [14]. It is also noteworthy to state that the various mechanisms proposed were not conclusive and needed to be revisited.

Iodine, on the other hand, is an essential component of the human diet, and in fact, appears to be the heaviest required element in a diet. Iodine compounds are useful in medicine and lack of iodine in the diet is a cause of goiter. Iodine is absolutely necessary for a healthy thyroid as well as ovaries, breasts, and prostate. Iodine deficiency is in fact the largest preventable cause of mental retardation worldwide [18]. In severe cases, it can result in cretinism, a form of mental retardation. These are just a few of the reasons why the study of iodine is also interesting. It is well known that iodine quantitatively oxidizes substances containing the $-\mathrm{NH}-\mathrm{NH}$ group. This reaction is the basis of one of the standard analytical procedures to titrate hydrazine 
and related substances, such as isonicotinoyl-hydrazide and hydrazobenzene, which are widely used in the pharmaceutical industry because of their bacteriostatic properties [19-22]. The mechanism of oxidation of hydrazine and its derivatives by iodine has been the subject of several studies, but among which no complete agreement was found [22-27]. A further investigation seemed desirable $[28,29]$.

In recent years, partly due to the development of new electronic techniques, a good deal of effort has been devoted to the study of reactions that are difficult to study by conventional methods. Molecular orbital calculations have been examined for complicated reaction systems that are difficult to study experimentally. However, only limited calculation has been done with 1,2-diphenylhydrazine and its derivatives, presumably due to the complication of these species. Computational chemistry methods can be used to explore the theoretical chemistry behind reactive systems, to compare the relative chemical reactivity of different systems and, by extension, to predict the reactivity of new systems. Semiempirical models AM1, PM3, and MNDO are often used in computational chemistry because they allow study of systems that are out of reach of the more accurate methods. These models are also used for systems that contain elements beyond 4th row of the periodic table [3035].

In theoretical studies using ab initio or density functional theory (DFT) methods, adequate choices of a theoretical method and a basis set are very important in obtaining reliable results. Unfortunately, for elements beyond the 4th row in the periodic table, basis sets are relatively limited, although various accurate theoretical methods such as B3LYP have been currently developed. Theoretical studies on compounds containing iodine, a 5th period halogen atom, are less abundant compared to those containing $\mathrm{F}, \mathrm{Cl}$, or $\mathrm{Br}$ which are 2nd, 3rd, and 4th elements, respectively. Heavy elements like iodine have a large number of core electrons which are in general less important for the chemical reactivity and bonding modes. However, it needs a large number of basis sets or functions to describe the corresponding orbitals. This makes computations with heavy elements like iodine very time consuming and expensive [10,36-38]. However, compounds containing iodine atom play very interesting and important roles in many chemical reactions, especially in the life sciences. Despite the challenges, this makes the study of Iodine quite interesting.

In the present paper we report the results of a computational studies on the mechanism of the oxidation of 1,2diphenylhydrazine, a derivative of hydrazine by iodine, which is important per se and also helps to shed light on the general mechanisms of oxidation of the - NH-NH-, by iodine. In this study, geometries of the reactants, intermediates, transition states, and products were examined using semiempirical and DFT methods to afford mechanistic insight into the 1,2-diphenylhydrazine/Iodine reaction by considering the stability of the intermediates and energies of the transition state [30-35]. Reacting species were first optimized using AMI, followed by PM3 and MNDO, then finally by the DFT method [10, 37-46]. For the density functional theory studies, geometry optimizations of all compounds and complexes were carried out at $6311+\mathrm{G}^{* *}$ basis set by using the B3LYP method of DFT for better results.

\section{Computational Methods}

The Spartan "14 v1.1.0 semiempirical (AMI, PM3, and MNDO) and DFT methods were used on Microsoft Windows XP professional version 2002 SP3 computer system, with Intel(R) Pentium(R) Dual CPU, E2200@2.20 GHz, 219 GHz, 3.24 GB of RAM."

The starting geometries for all of the semi empirical and DFT calculations were first optimized and calculated using AMI method. The AM1 optimized species were further reoptimized using PM3 method. The PM3 optimized species were then used for the respective MNDO and the DFT calculations. Before each calculation was submitted, the "Global Calculations" option was selected in the workspace. For the density functional theory studies, geometry optimizations of all compounds and complexes were carried out at 6311 $+\mathrm{G}^{* *}$ basis set by using the B3LYP method of DFT [37]. The optimized geometries of the reactants, intermediates, transition states, and products were confirmed in terms of vibrational analysis [23]. The transition state for each step was located and confirmed by animating the vibration corresponding to the reaction coordinate by selecting the imaginary frequency at the top of the list of frequencies on the IR tab. No arbitrary assumptions were imposed on finding the most likely geometries for the transition state in each case.

\section{Results and Discussion}

3.1. Published Mechanism. The outline of the published mechanism of the reaction of 1,2-diphenylhydrazine with Iodine as given by May and Halpern [11] is shown as follows for the chain multistep mechanism:

$$
\begin{gathered}
\mathrm{AH}_{2}+\mathrm{I}_{2} \longrightarrow \mathrm{AH}_{\bullet}+\mathrm{HI}+\mathrm{I}_{\bullet} \\
\mathrm{AH}_{2}+\mathrm{I}_{\bullet} \longrightarrow \mathrm{AH}+\text { + HI } \\
\mathrm{AH}_{\bullet}+\mathrm{I}_{2} \longrightarrow \mathrm{A}+\mathrm{HI}+\mathrm{I}_{\bullet} \\
2 \mathrm{AH}_{\bullet} \longrightarrow \mathrm{A}+\mathrm{AH}_{2}
\end{gathered}
$$

According to the mechanisms outlined above where $\mathrm{AH}_{2}$, 1,2-diphenylhydrazine; $\mathrm{AH}$, a 1,2-diphenyl-hydrazyl radical; $\mathrm{A}$, the trans-1,2-diphenyldiazene (Azobenzene); $\mathrm{I}_{2}$, iodine molecule; HI, hydrogen iodide and I, iodide ion, the overall equation of reaction should be as in (5) below, if (1)-(5) are summed up:

$$
\mathrm{AH}_{2}+2 \mathrm{I}_{2}+\mathrm{AH} \longrightarrow 2 \mathrm{~A}+3 \mathrm{HI}+\mathrm{I}
$$

Whalley et al. [12] in their work published a similar mechanism for the reaction of 1,2-diphenylhydrazine with persulphate. However, these two separate studies [11, 12] gave stoichiometry equations of the type as in (6), which is not consistent with their given mechanisms:

$$
\mathrm{AH}_{2}+\mathrm{I}_{2} \longrightarrow \mathrm{A}+2 \mathrm{HI}
$$


TABLE 1: Heat of formation and other activation parameters of reacting species.

\begin{tabular}{|c|c|c|c|c|c|}
\hline \multirow{2}{*}{$\mathrm{S} / \mathrm{N}$} & \multirow{2}{*}{ Reacting species } & \multirow{2}{*}{$\begin{array}{l}\text { Heat of formation at } 298.15 \mathrm{~K} \text { using DFT } \\
\qquad E(\mathrm{~kJ} / \mathrm{mol})\end{array}$} & \multicolumn{3}{|c|}{ Activation parameters at $298.15 \mathrm{~K}$ using MNDO } \\
\hline & & & $\Delta H^{\circ}(\mathrm{kJ} / \mathrm{mol})$ & $\Delta G^{\circ}(\mathrm{kJ} / \mathrm{mol})$ & $\Delta S^{\circ}(\mathrm{kJ} / \mathrm{mol} \cdot \mathrm{K})$ \\
\hline 1 & $\mathrm{I}_{2}$ & $-37,327,532.08$ & 114.05 & 36.73 & 259.34 \\
\hline 2 & $\mathrm{AH}_{2}$ & $-1,507,000.75$ & 952.60 & 818.08 & 451.19 \\
\hline 3 & $\mathrm{TS}_{1}$ & $-31,804,644.68$ & 1089.71 & 911.31 & 598.35 \\
\hline 4 & $\mathrm{AH}$ & $-1,505,357.68$ & 849.15 & 716.12 & 446.20 \\
\hline 5 & $\mathrm{HI}$ & $-18,168,774.40$ & 119.36 & 57.88 & 206.18 \\
\hline 6 & $\mathrm{I}^{-}$ & $-18,157,470.45$ & 0.00 & & \\
\hline 7 & $\mathrm{TS}_{2}$ & $-19,669,188.83$ & 1766.33 & 1574.84 & 642.26 \\
\hline 8 & $\mathrm{TS}_{3}$ & $-36,834,591.95$ & & & \\
\hline 9 & $\mathrm{~A}$ & $-1,503,817.83$ & 900.32 & 769.20 & 439.76 \\
\hline 10 & TS* & $-37,824,591.91$ & 1111.05 & 934.95 & 590.65 \\
\hline
\end{tabular}

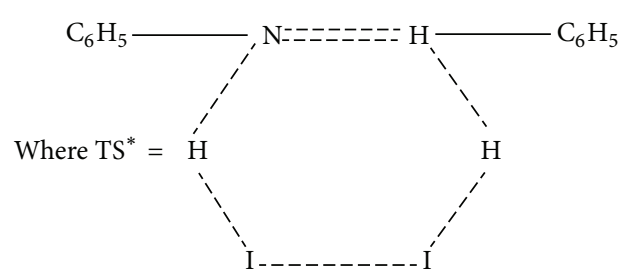

Scheme 1: The one step mechanism with cyclic activated complex.

Another study [18] in which 1,2-diphenylhydrazine was oxidized by molecular oxygen was reported to show a stoichiometry similar to (6). The equation is given (7) below:

$$
\mathrm{AH}_{2}+\mathrm{O}_{2} \longrightarrow \mathrm{A}+\mathrm{H}_{2} \mathrm{O}_{2}
$$

May and Halpern [11] did provide an alternative one step mechanism in which "cyclic" activated complex was formed which disproportionates to give products that are consistent with (6). The authors [11] were of the opinion that both the chain multistep mechanism proposed in (1)-(4) and the onestep mechanism, as shown in (8) in Scheme 1, were plausible mechanisms. It is the desire of this study to investigate whether the popular multistep mechanism [11, 12] or the latter proposed one-step mechanism is the most plausible one and/or if both routes are possible, which would be the most favored:

$$
\mathrm{AH}_{2}+\mathrm{I}_{2} \longrightarrow\left[\mathrm{TS}^{*}\right] \longrightarrow \mathrm{A}+2 \mathrm{HI}
$$

\subsection{Geometry Optimization of Intermediates and Transition} States; Validity of the Generally Accepted Mechanism. Geometry optimization of the reactants, intermediates, transition states, and products in the 1,2-diphenylhydrazine reaction with iodine was executed. The geometry optimizations of all these species were successfully completed and the heat of formation $\left(\Delta H_{f}\right)$ was evaluated and presented in Table 1.

The optimized geometries of the reactants, intermediates, transition states, and products are shown in Figure 1.

3.3. Proposal of a More Plausible Mechanism for the Reaction. According to the discussion that will follow on the basis of the semiempirical calculations as well as the DFT calculations, the mechanism shown in Scheme 2 for the chain multistep mechanism is more plausible than the mechanism version published by May and Halpern [11]. Scheme 2 can be presented in a simplified form as (9) through (11):

$$
\begin{gathered}
\mathrm{AH}_{2}+\mathrm{I}_{2} \stackrel{k_{1}}{\longrightarrow} \mathrm{AH}+\mathrm{HI}+\mathrm{I}^{\bullet} \\
\mathrm{AH}^{\bullet}+\mathrm{I}_{2} \underset{\text { slow }}{\stackrel{k_{2}}{\longrightarrow}} \mathrm{A}+\mathrm{HI}+\mathrm{I}^{\bullet} \\
\mathrm{AH}_{2}+2 \mathrm{I}^{\bullet} \underset{\text { fast }}{\stackrel{k_{3}}{\longrightarrow}} \mathrm{A}+2 \mathrm{HI}
\end{gathered}
$$

So that the overall equation of the reaction is as given in (12)

$$
2 \mathrm{AH}_{2}+2 \mathrm{I}_{2} \longrightarrow 2 \mathrm{~A}+4 \mathrm{HI}
$$

Or, as in (13) which is in agreement with (6) above and is consistent with the mechanism proposed:

$$
\mathrm{AH}_{2}+\mathrm{I}_{2} \longrightarrow \mathrm{A}+2 \mathrm{HI}
$$

Step 1 (see (9)). The optimized 1,2-diphenylhydrazine $\left(\mathrm{AH}_{2}\right)$ reacted with the iodine molecule $\left(\mathrm{I}_{2}\right)$ to yield a 1,2diphenylhydrazyl radical $\left(\mathrm{AH}^{*}\right)$, hydrogen iodide $(\mathrm{HI})$, and iodine radical $\left(\mathrm{I}^{*}\right)$ via the transition state $\mathrm{TS}_{1}$. This step is in agreement with (1) proposed by May and Halpern [11].

Step 2 (see (10)). The optimized 1,2-diphenylhydrazyl radical $(\mathrm{AH})$ reacted with another iodine molecule $\left(\mathrm{I}_{2}\right)$ to give trans-1,2-diphenyldiazene (A), the reported product of 1,2diphenylhydrazine oxidation via the transition state $\mathrm{TS}_{2}$. This step was the rate determining step, as shown by the high value of $\Delta H_{f}$ in Table 1. Equation (10) differed from (2) but rather agreed with (3).

Step 3 (see (11)). Another optimized 1,2-diphenylhydrazine $\left(\mathrm{AH}_{2}\right)$ reacted with iodine radicals produced in Steps 1 and 2. This reaction was fast to yield another oxidation product, trans-1,2-diphenyldiazene (A) plus two molecules of hydrogen iodide. The energy for the combination of two molecules 1,2-diphenylhydrazyl radicals ( $\mathrm{AH}$.), as reported 


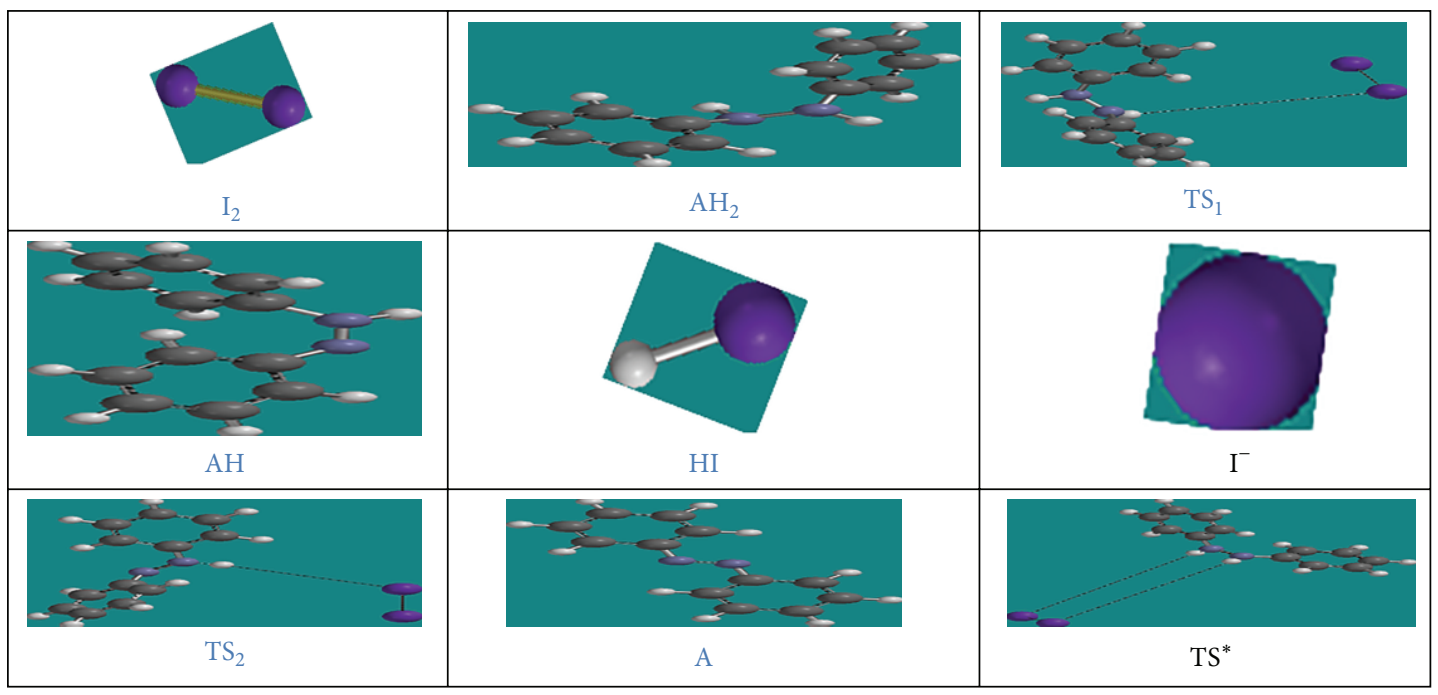

FIGURE 1: Optimized geometries of the reactants, intermediates, transition states, and products.
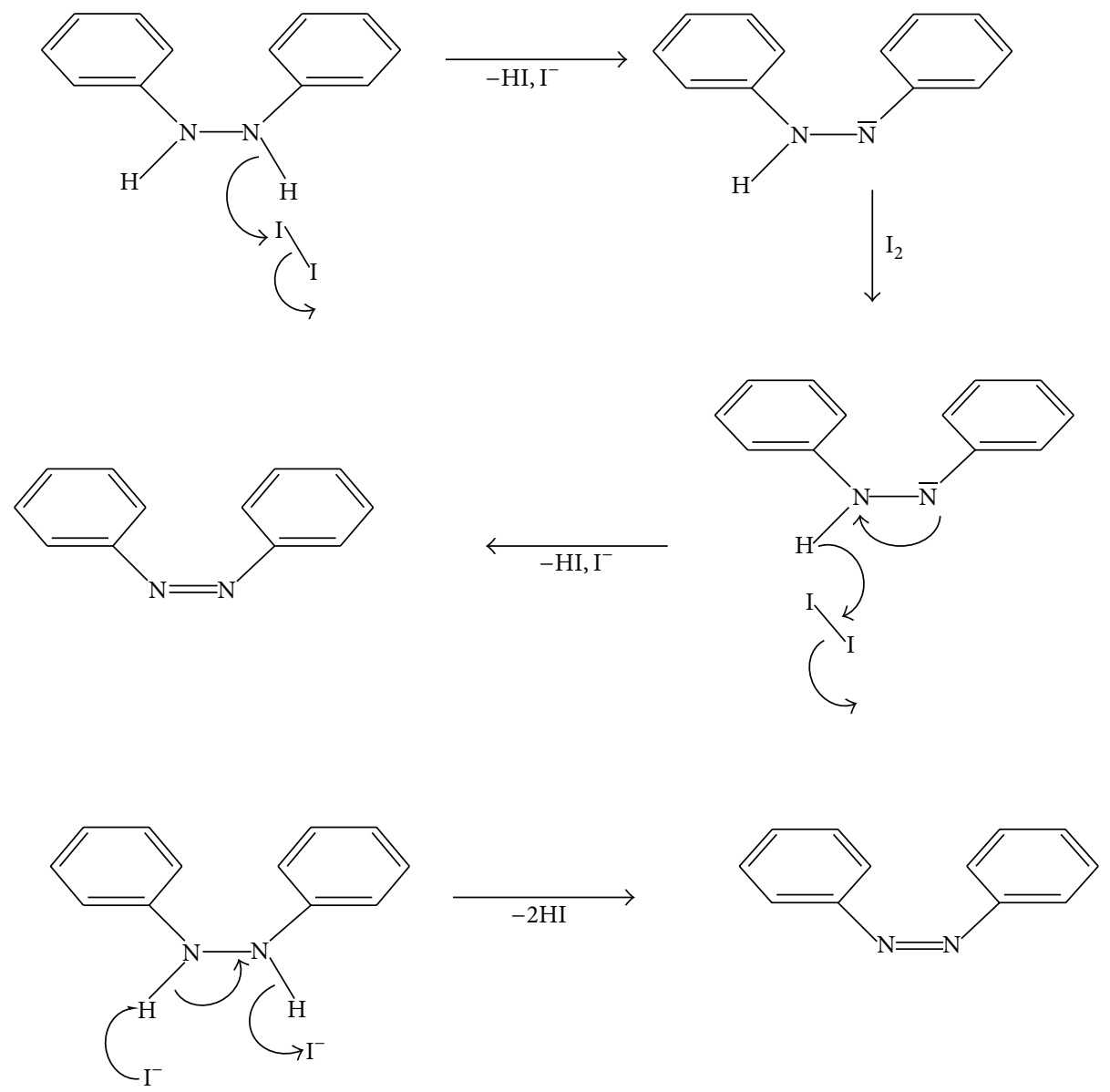

Scheme 2: Proposed multistep mechanism for the 1,2-diphenylhydrazine reaction with Iodine. 


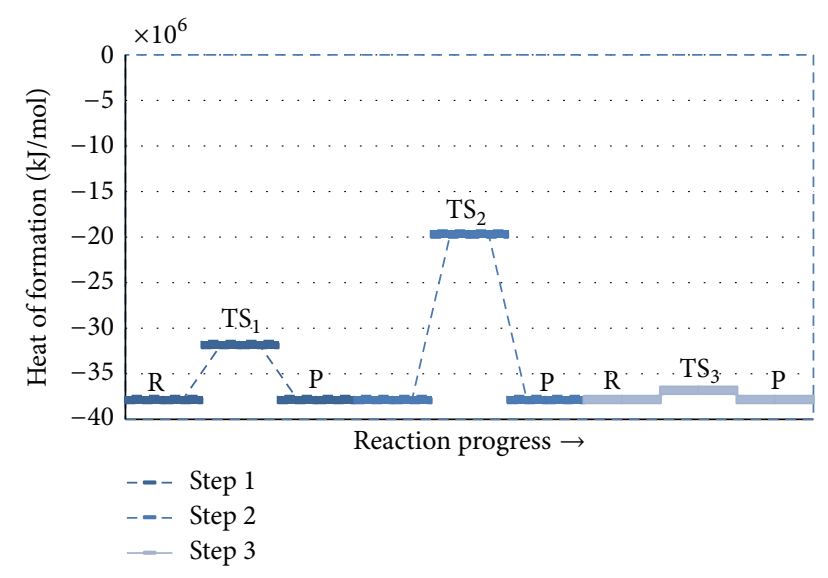

(a)

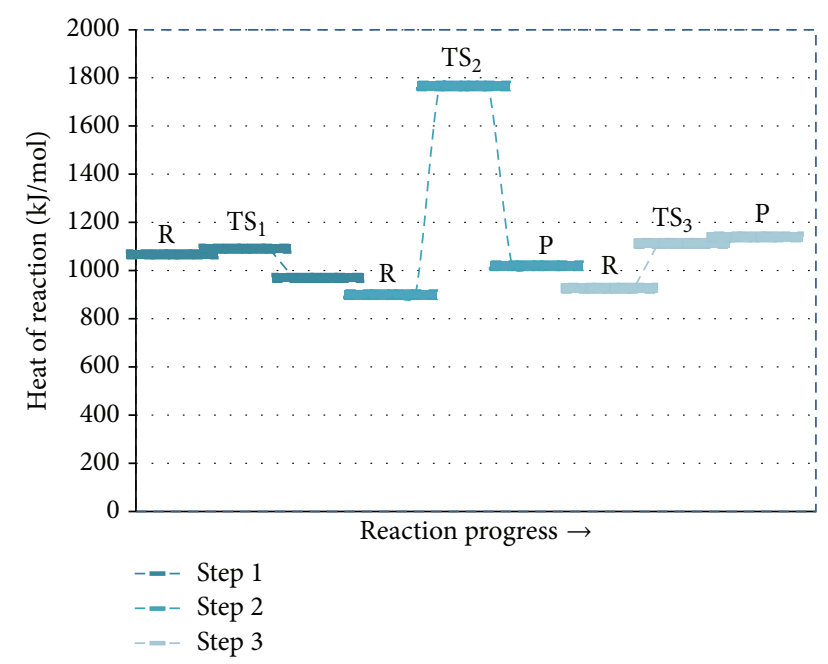

(b)

Figure 2: (a) Energy profile of the oxidation of 1,2diphenylhydrazine by iodine as per the DFT calculations. (b) Energy profile of the oxidation of 1,2-diphenylhydrazine by iodine as per the MNDO calculations.

by May and Halpern [11] in (4), was very high in comparison to that required for (11) reported for this study.

The summation of (9), (10), and (11) gave (12), which was reduced to (13). Equation (13) is the exact stoichiometric equation for the oxidation of 1,2-diphenylhydrazine as reported by previous works $[1,11,12]$.

Figures 2(a) and 2(b) below depict the three steps mechanism of the oxidation of 1,2-diphenylhydrazine by iodine diagrammatically, as per the DFT and semiempirical calculations, respectively, with the positions of the various species ( $\mathrm{R}$, reactants; $\mathrm{TS}^{1-3}$, transition states and $\mathrm{P}$, products) indicated. From the scaled diagrams it was evident that Step 2 was the rate determining step as shown by the high position of the transition state, $\mathrm{TS}_{2}$ in both diagrams. Based on the optimized geometries of the reacting species, an attempt was made to search the transition states in each of the Steps 1,2 , and 3 . Only one transition state was found for each step as shown in Figures 2(a) and 2(b) and summarized in Table 1 (transition state in Step 1: $\mathrm{TS}_{1}$, in Step 2: $\mathrm{TS}_{2}$ ). Vibrational analysis confirmed that $\mathrm{TS}_{1}$ and $\mathrm{TS}_{2}$ were actually the transition state in each step, while $\mathrm{TS}_{3}$ was not a true transition state. The $\Delta H_{f}$ of $\mathrm{TS}_{1}$ and $\mathrm{TS}_{2}$ were calculated to be $-31,804,644.68$ and $-19,669,188.83 \mathrm{~kJ} / \mathrm{mol}$, respectively, for the DFT calculations while the semiempirical calculations of the values were 1089.71 and $1766.33 \mathrm{~kJ} / \mathrm{mol}$, respectively. Based on the above results, the apparent activation energies for Steps 1 to 3 were estimated by subtracting the $\Delta H_{f}$ of the starting geometry from that of the transition state in each step in order to determine the rate-determining step. As shown in Figures 2(a) and 2(b), it was found that the transition state $\mathrm{TS}_{2}$ had the largest $\Delta H_{f}$. Thus, the apparent activation energy for Step 2 was estimated to be $18,163,700.93 \mathrm{~kJ} / \mathrm{mol}$ for DFT estimations and $803.13 \mathrm{~kJ} / \mathrm{mol}$ for MNDO estimations, whereas for Step 1, it was found to be just $6,029,888.15$ or $23.06 \mathrm{~kJ} / \mathrm{mol}$, respectively. This clearly indicated that Step 1 proceeded very smoothly. On the other hand, in Step 2 the activation energy was significantly large $(18,163,700.93 \mathrm{~kJ} / \mathrm{mol}$ or $803.13 \mathrm{~kJ} / \mathrm{mol}$ ) in comparison with those in other steps. For Step 3, true transition state was not found.

For the one step mechanism in which "cyclic" activated complex was formed, the energy diagrams according to the DFT and MNDO estimations for the reaction were given in Figures 3(a) and 3(b). Based on the optimized geometries of the reacting species, an attempt was made to search the transition states also, which was found and confirmed by vibrational analysis. The transition state, TS*, as optimized and shown in Figure 1, has the $\Delta H_{f}$, estimated to be $-37824591.91 \mathrm{~kJ} / \mathrm{mol}$ or $1111.05 \mathrm{~kJ} / \mathrm{mol}$, respectively. The apparent activation energy was estimated to be $9,940.92$ or $44.40 \mathrm{~kJ} / \mathrm{mol}$, thus indicating that the reaction could proceed smoothly too. In fact, the activation barrier of $9,940.92$ or $44.40 \mathrm{~kJ} / \mathrm{mol}$ for the limiting step of the "cyclic" activated complex mechanism was a pointer that this mechanism would be more favored than the multistep chain mechanism which had an activation barrier of $18,163,700.93$ or $803.13 \mathrm{~kJ} / \mathrm{mol}$ for the rate limiting step.

\subsection{Enthalpy of Reaction and Rate Constant Calculations} $[17,45,46]$. The enthalpies of reaction were calculated by using the Spartan software to calculate heats of formation at standard temperature of $298.15 \mathrm{~K}$, and the appropriate sums and differences taken as given in (14):

$$
\begin{aligned}
\Delta_{r} H^{o}(298.15 \mathrm{~K})= & \sum_{\text {products }} \Delta_{f} H_{\text {prod }}^{o}(298.15 \mathrm{~K}) \\
& -\sum_{\text {reactants }} \Delta_{f} H_{\text {react }}^{o}(298.15 \mathrm{~K}) .
\end{aligned}
$$

The computed enthalpies of reaction at standard conditions was $72.39 \mathrm{~kJ} / \mathrm{mol}$ for both the mechanisms considered in this work as compared to the computed enthalpies of reaction of the mechanism proposed by May and Halpern [11], which was $128.87 \mathrm{~kJ} / \mathrm{mol}$ at $298.15 \mathrm{~K}$. 


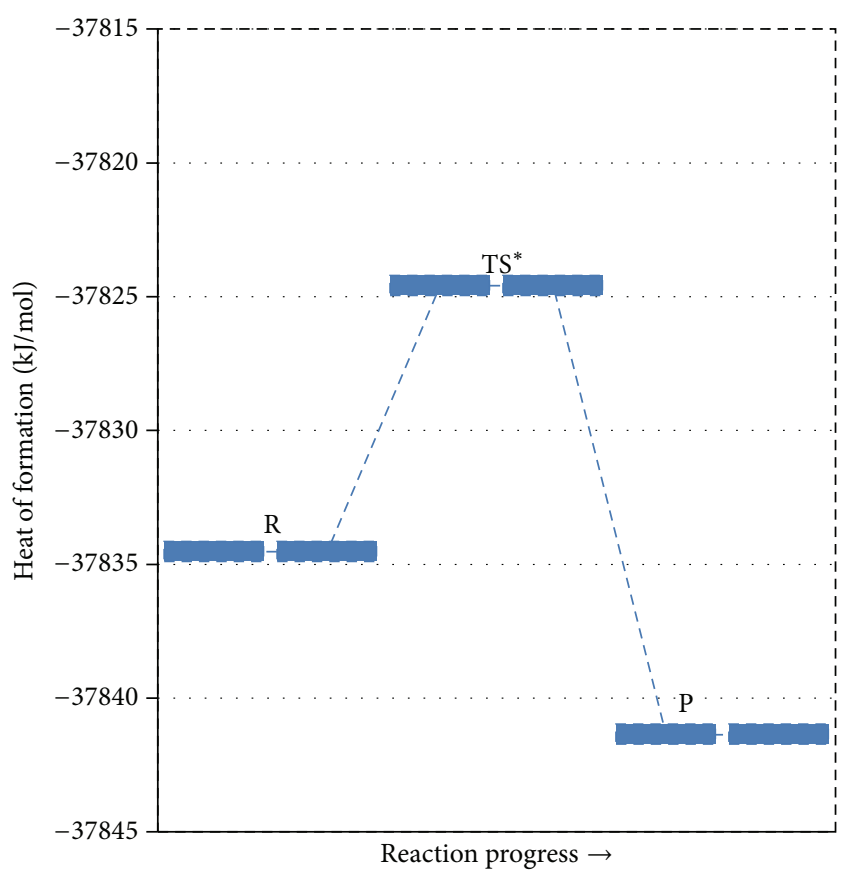

(a)

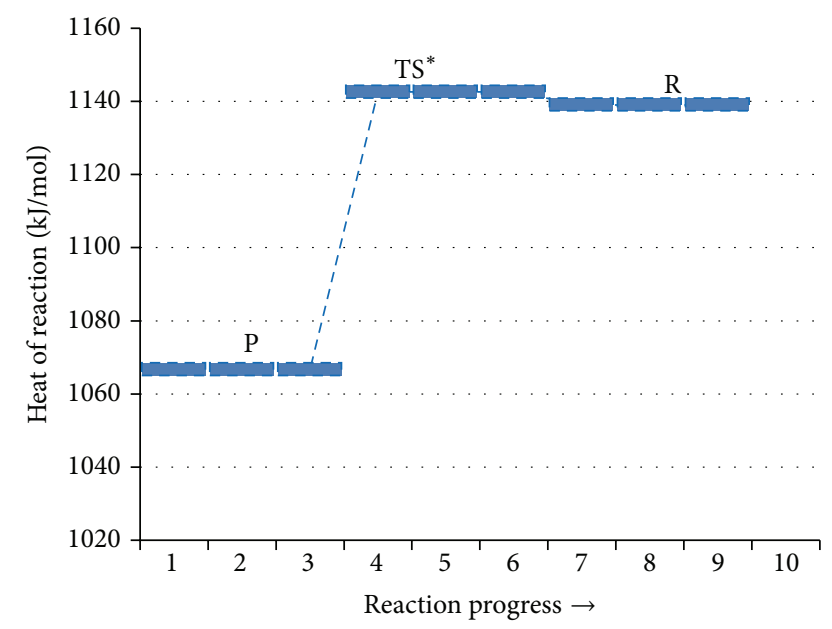

(b)

FIGURE 3: (a) Energy profile of the oxidation of 1,2diphenylhydrazine by iodine via the cyclic activated complex for the DFT calculations. (b) Energy profile of the oxidation of 1,2-diphenylhydrazine by iodine via the cyclic activated complex for the MNDO calculations.

The rate constant calculations were computed according to the following:

$$
k(298.15 \mathrm{~K})=\frac{k_{B} T}{h c^{o}} e^{-\Delta \ddagger G^{o} / R T},
$$

where $k(298.15 \mathrm{~K})$ is the reaction rate at temperature $(298.15 \mathrm{~K}) ; k_{B}$ is the Boltzmann constant $(1.380662 \times$ $\left.10^{-23} \mathrm{~J} / \mathrm{K}\right) ; T$ is temperature $(298.15 \mathrm{~K}) ; h=$ Planck's constant $\left(6.626176 \times 10^{-34} \mathrm{Js}\right) ; c^{o}$ is concentration (taken to be 1$) ; \Delta \ddagger G^{o}$ is Gibbs free energy of activation $(\mathrm{kJ} / \mathrm{mol}) ; R$ is gas constant $(8.31441 \mathrm{~J} / \mathrm{mol} \cdot \mathrm{K})$.
The rate constants, $k_{1}$ and $k_{2}$, for this study, as proposed in the mechanisms in Scheme 2 were $7.85 \mathrm{~mol}^{-1} \mathrm{sec}^{-1}$ and $1.88 \times 10^{9} \mathrm{~mol}^{-1} \mathrm{dm}^{-3} \mathrm{sec}^{-1}$, respectively, as opposed to the mechanisms in (1)-(4) published previously [11], where $k_{1}=$ $5.76 \times 10^{8} \mathrm{~mol}^{-1} \mathrm{sec}^{-1}$ and $k_{2}=3.35 \times 10^{8} \mathrm{~mol}^{-1} \mathrm{sec}^{-1}$, respectively. The foregoing showed that the mechanisms proposed in Scheme 2 are more favorable than those proposed in (1)(4) published by May and Halpern [11], as it was reported that the larger the value of the rate constant, the faster the reaction [47]. The rate constant for the one-step cyclic activated complex mechanism was computed to be $5.67 \times 10^{-2} \mathrm{sec}^{-1}$. The multistep mechanisms were less favored than the one step mechanism, especially if we take into account that activation barrier of $18,163,700.9393 \mathrm{~kJ} / \mathrm{mol}$ in the limiting step for the multistep mechanisms for the DFT calculations which was far more than the $9,940.92 \mathrm{~kJ} / \mathrm{mol}$ for the limiting step of the one-step cyclic activated complex mechanism.

\section{Conclusion}

The mechanism of the reaction of 1,2-diphenylhydrazine with iodine was studied using computational semiempirical and density functional theory methods. The results of this study were compared with previously published work on the reaction of 1,2-diphenylhydrazine with iodine. This work proposed a modified multistep mechanism that was consistent with the stoichiometry of reaction as opposed to the mechanisms previously published. This work was also able to demonstrate that even though the multistep mechanisms and the one-step cyclic activated complex mechanism were possible, the one-step cyclic activated complex mechanism was more favorable.

\section{Conflict of Interests}

The authors declare that there is no conflict of interests regarding the publication of this paper.

\section{References}

[1] T. J. Kelly, R. Mukund, C. W. Spicer, and A. J. Pollack, "Concentrations and trapsformations of hazardous air pollutants," Environmental Science and Technology, vol. 28, no. 8, pp. 378A387A, 1994.

[2] IPCS, International Chemical Safety Card for 1,2-Diphenylhydrazine, International Programme for Chemical Safety WHO, Geneva, Switzerland, 1993.

[3] S. Ohnishi, M. Murata, S. Oikawa, Y. Hiraku, and S. Kawanishi, "Copper-dependent DNA damage induced by hydrazobenzene, an azobenzene metabolite," Free Radical Research, vol. 32, no. 6, pp. 469-478, 2000.

[4] M. J. Zdilla, A. K. Verma, and S. C. Lee, "Reactivity of a sterically hindered $\mathrm{Fe}(\mathrm{II})$ thiolate dimer with amines and hydrazines," Inorganic Chemistry, vol. 47, no. 23, pp. 11382-11390, 2008.

[5] S. Globig and K. J. Freundt, "Metabolism of hydrazobenzene in rat liver homogenate, Autumn Meeting of the Deutsche Gesellschaft Fuer Experimentelle Und Klinische PharmakologieUnd Toxikologie (German Society for Experimental and Clinical Pharmacology and Toxicology), Dresden, Germany, 
September 10-12, 1996," Naunyn-Schmiedeberg's Archives of Pharmacology, vol. 354, no. 4, supplement 1, article R28, 1996.

[6] S. Globig, M. Killguss, and K. J. Freundt, "Metabolism of hydraobenzene and azobenzene in rat hepatocytes in primary culture, Autumn Meeting of the Deutsche Gesellschaft Fuer Experimentelle Und Klinische Pharmakologie Und Toxikologie (German Society for Experimental and Clinical Pharmacology and Toxicology), Dresden, Germany, September 10-12, 1996," Naunyn-Schmiedeberg's Archives of Pharmacology, vol. 354, no. 4, supplement 1, article R419, 1996.

[7] A. Assi, S. Globig, and C. Koelbel, "Ph-dependent reaction types of hydrazobenzene in gastric juice and hydrous solution, 37th Spring Meeting of the German Society for Experimental and Clinical Pharmacology and Toxicology, Mainz, Germany, March 12-14, 1996," Naunyn-Schmiedeberg's Archives of Pharmacology, vol. 353, no. 4 supplement, article R112, 1996.

[8] M. S. Khalil, N. Kelada, B. Sawyer, D. R. Zenz, P. Tata, and C. Lue-Hing, "Comparison of one-step acidic extraction versus two-step basic and acidic extraction procedures for semivolatile analysis of wastewater," Water Environment Research, vol. 71, no. 3, pp. 348-354, 1999.

[9] R. B. Homer, R. D. Cannon, and S. S. B. Kim, "The oxidation of hydrazobenzene by oxygen catalyzed by $\mathrm{CO}(2 \mathrm{MeOsalen})$ in methanol," Bulletin of the Korean Chemical Society, vol. 6, no. 2, pp. 115-118, 1985.

[10] K. Ayub and T. Mahmood, "DFT studies of halogen bonding abilities of nitrobenzene with halogens and chlorofluorocarbons," Journal of Chemical Society of Pakistan, vol. 35, no. 3, pp. 617-821, 2013.

[11] J. W. May and J. Halpern, "Kinetics of the oxidation of hydrazobenzeneby iodine and triiodide," Canadian Journal of Chemistry, vol. 39, no. 6, pp. 1377-1385, 1961.

[12] B. J. P. Whalley, H. G. V. Evans, and C. A. Winkler, "The oxidation of hydrazobenzene by ammonium persulphate in acetonitrile-water solution," Canadian Journal of Chemistry, vol. 34, no. 9, pp. 1154-1162, 1956.

[13] W. J. Zubyk, Dissertation [Ph.D. thesis], University of Delaware, 1957.

[14] K. J. Blackmore, N. Lal, J. W. Ziller, and A. F. Heyduk, "Catalytic reactivity of a zirconium(IV) redox-active ligand complex with 1,2-diphenylhydrazine," Journal of the American Chemical Society, vol. 130, no. 9, pp. 2728-2729, 2008.

[15] R. A. Zarkesh, J. W. Ziller, and A. F. Heyduk, "Four-electron oxidative formation of aryl diazenes using a tantalum redoxactive ligand complex," Angewandte Chemie-International Edition, vol. 47, no. 25, pp. 4715-4718, 2008.

[16] T. X. T. Luu, P. Christensen, F. Duus, and T. N. Le, "Inorganic salt supported potassium permanganate promoted oxidation of aniline into azobenzene," Journal of Chemistry, vol. 45, pp. 1051110, 2007.

[17] J. W. Ochterski, “Thermochemistry in Gaussian," Technical Support Information, gaussian.com, pp. 1-19, 2000.

[18] X.-Y. Cao, X.-M. Jiang, A. Kareem et al., "Iodination of irrigation water as a method of supplying iodine to a severely iodinedeficient population in Xinjiang, China," The Lancet, vol. 344, no. 8915 , pp. 107-110, 1994.

[19] S. M. Sultan, I. Z. Alzamil, A. M. Al-Hajjaji, S. A. Al-Tamrah, and A. M. A. Al-Rahman, "A kinetic study on the determination of hydrazine by iodine in sulphuric acid media," Journal of Chemical Society of Pakistan, vol. 7, no. 2, pp. 93-99, 1985.

[20] K. J. Laidler, Physical Chemistry with Biological Applications, The Benjamin Cumming, San Francisco, Calif, USA, 1978.
[21] T. S. Rao and P. S. Dalvi, "Kinetics and mechanism of the rapid oxidation of hydrazine by iodine in weakly acidic solutions," Proceeding Indian National Science Academy, vol. 56, no. 2, pp. 153-160, 1990.

[22] I. A. Funai and M. A. Blesa, "Kinetics and mechanism of the reaction of iodine with isonicotinoylhydrazide," Canadian Journal of Chemistry, vol. 62, no. 12, pp. 2923-2928, 1984.

[23] M. S. Mshelia, F. Iyun, A. Uzairu, and S. Idris, "Kinetics and mechanism of the oxidation of hydrazine dihydrochloride by aqueous iodine," Journal of American Science, vol. 6, no. 9, pp. 293-296, 2010.

[24] K. Mitteilung, "Kinetics of reaction between hydrazine and iodine solution," Zeitschrift für Physikalische Chemie Nexie Folge, vol. 45, no. 5-6, pp. 378-382, 1965.

[25] S. E. King, J. N. Cooper, and R. D. Crawford, "Oxidation of hydrazine by iodine in aqueous perchloric acid," Inorganic Chemistry, vol. 17, no. 11, pp. 3306-3307, 1978.

[26] D. A. Palmer and M. H. Lietzke, "The equilibria and kinetics of iodine hydrolysis," Radiochim Acta, vol. 31, pp. 37-44, 1982.

[27] R. M. Smith and A. E. Martell, Critical Stability Constant, vol. 4, Plenum Press, New York, NY, USA, 1976.

[28] P. Bhatnagar, R. K. Mittal, and Y. K. Gupta, "Stoicheiometry, kinetics, and mechanism of the oxidation of hyponitrous acid by iodine in acetate buffers," Journal of the Chemical Society, Dalton Transactions, no. 12, pp. 3669-3673, 1990.

[29] A. Mondal and R. Banerjee, "Kinetics and mechanism of uncatalyzed oxidation of hydrazine with superoxide coordinated to cobalt(III)," Indian Journal of Chemistry A, vol. 48, no. 5, pp. 645-649, 2009.

[30] D. C. Young, "Semi empirical methods," in Computational Chemistry: A Practical Guide for Applying Techniques to Real World Problems, John Wiley \& Sons, New York, NY, USA, 2002.

[31] Spartan User's Guide, version 3. 0, Wavefunction, 1993.

[32] K. Kahn and T. C. Bruice, “Transition-state and ground-state structures and their interaction with the active-site residues in catechol O-methyltransferase," Journal of the American Chemical Society, vol. 122, no. 1, pp. 46-51, 2000.

[33] K. Kahn and P. A. Tipton, "Kinetics and mechanism of allantoin racemization," Bioorganic Chemistry, vol. 28, no. 2, pp. 62-72, 2000 .

[34] K. Kahn, "Theoretical study of intermediates in the urate oxidase reaction," Bioorganic Chemistry, vol. 27, no. 5, pp. 351$362,1999$.

[35] J. J. P. Stewart, "Optimization of parameters for semiempirical methods V: modification of NDDO approximations and application to 70 elements," Journal of Molecular Modeling, vol. 13, no. 12, pp. 1173-1213, 2007.

[36] J. Marten, W. Seichter, E. Weber, and U. Böhme, "Crystalline packings of diketoarylhydrazones controlled by a methyl for trifluoromethyl structural change," CrystEngComm, vol. 10, no. 5, pp. 541-547, 2008.

[37] J. Zhang and W. L. Hase, "Electronic structure theory study of the $\mathrm{F}^{-}+\mathrm{CH}_{3} \mathrm{I} \rightarrow \mathrm{FCH}_{3}+\mathrm{I}^{-}$Potential Energy Surface," The Journal of Physical Chemistry A, vol. 114, no. 36, pp. 9635-9643, 2010.

[38] F. Jensen, Introduction to Computational Chemistry, John Wiley \& Sons, Chichester, UK, 1999.

[39] J. Castells, F. Geijo, and F. López-Calahorra, "The "formoin reaction" : a promising entry to carbohydrates from formaldehyde," Tetrahedron Letters, vol. 21, no. 47, pp. 4517-4520, 1980. 
[40] F. Jordan, "Theoretical studies on thiamin action, conformation of 2-1-hydroxethylthiamine," Journal of American Chemical Society, vol. 98, pp. 808-813, 1976.

[41] W. Shin, D.-G. Oh, C.-H. Chae, and T.-S. Yoon, "Conformational analyses of thiamin-related compounds: a stereochemical model for thiamin catalysis," Journal of the American Chemical Society, vol. 115, no. 26, pp. 12238-12250, 1993.

[42] A. A. Shaffer and S. G. Wierschke, "Comparison of computational methods applied to oxazole, thiazole, and other heterocyclic compounds," Journal of Computational Chemistry, vol. 14, no. 1, pp. 75-88, 1993.

[43] F. T. Burling and B. M. Goldstein, "Computational studies of nonbonded sulfur-oxygen and selenium-oxygen interactions in the thiazole and selenazole nucleosides," Journal of the American Chemical Society, vol. 114, no. 7, pp. 2313-2320, 1992.

[44] S. Kabirand and A. M. Sapse, "An ab initio study of the proton affinities of some heteroatomic rings: Imidazole, oxazole, and thiazole," Journal of Computational Chemistry, vol. 12, no. 9, pp. 1142-1146, 1991.

[45] F. Mari, P. M. Lahti, and W. E. McEwen, "A theoretical study of the Wittig olefination reaction: MNDO-PM3 treatment of the Wittig half-reaction of unstabilized ylides with aldehydes," Journal of the American Chemical Society, vol. 114, no. 3, pp. 813821, 1992.

[46] T. Engel and P. Reid, Physical Chemistry, Pearson Prentice Hall, Upper saddle River, NJ, USA, 2006.

[47] R. P. Szajewski and G. M. Whitesides, "Rate constants and equilibrium constants for thiol-disulfide interchange reactions involving oxidized Glutathione," Journal of the American Chemical Society, vol. 102, no. 6, pp. 2011-2026, 1980. 

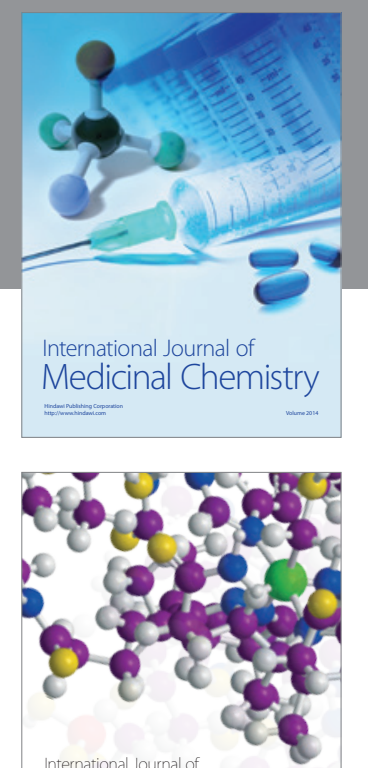

\section{Carbohydrate} Chemistry

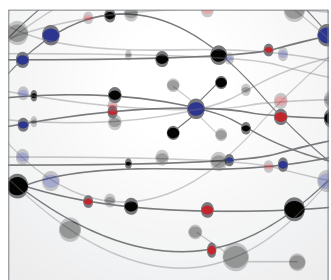

The Scientific World Journal
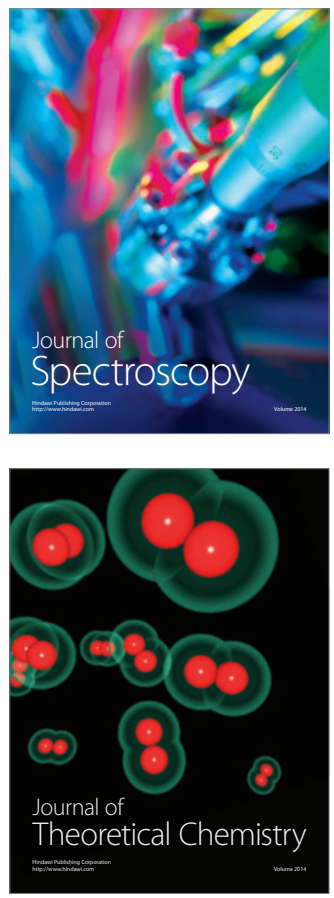
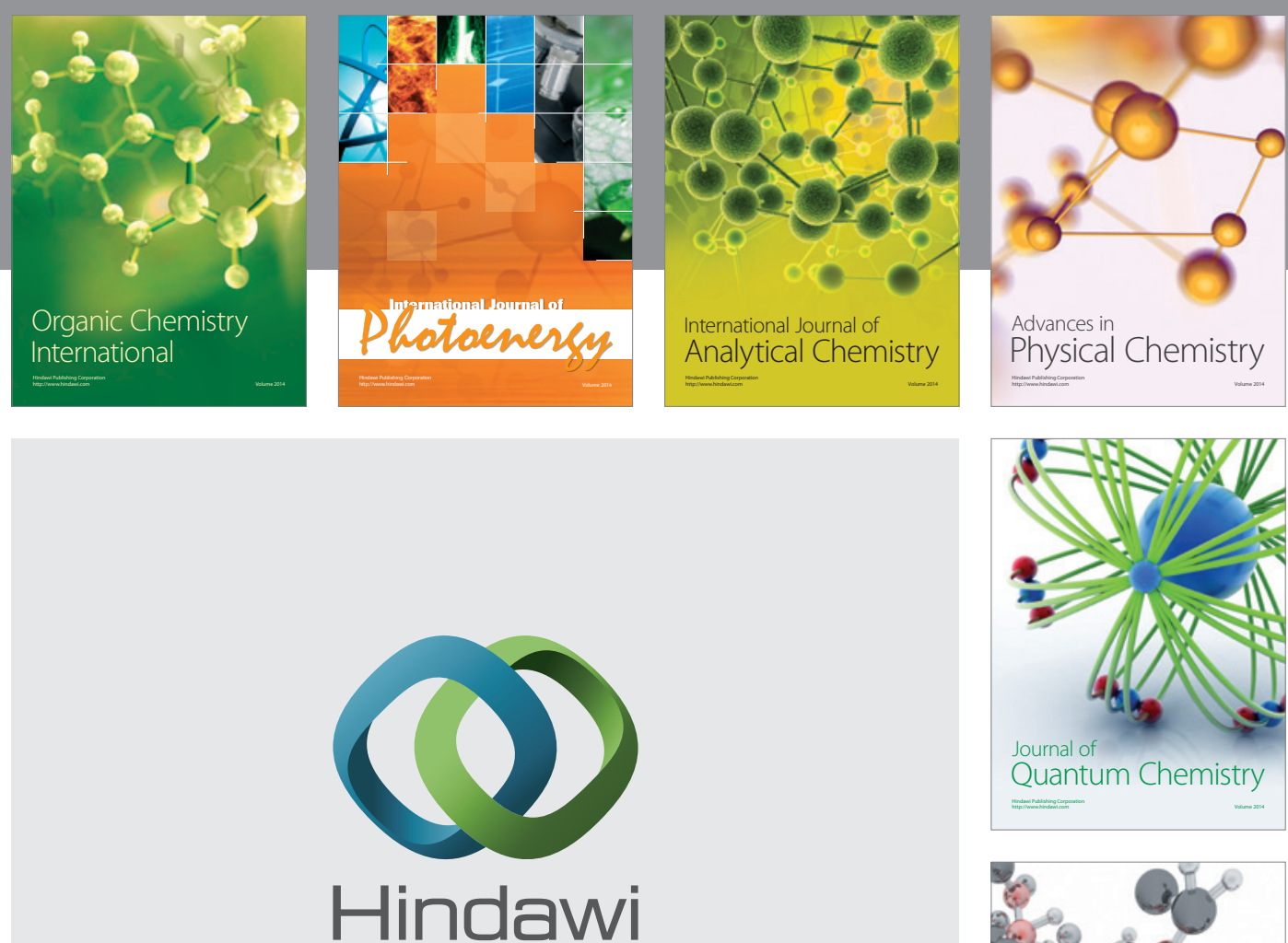

Submit your manuscripts at

http://www.hindawi.com

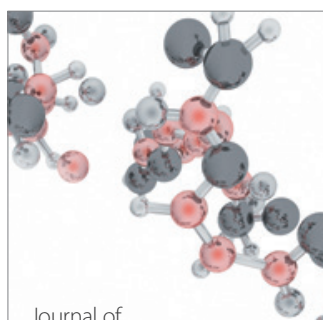

Analytical Methods

in Chemistry

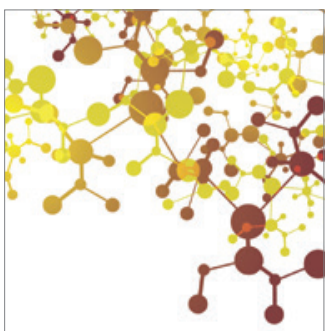

Journal of

Applied Chemistry

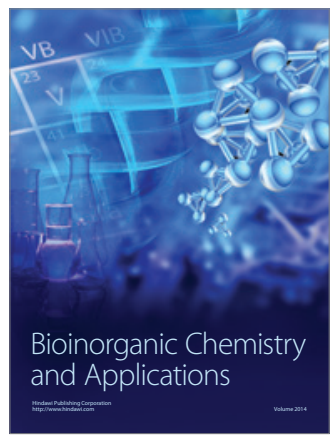

Inorganic Chemistry
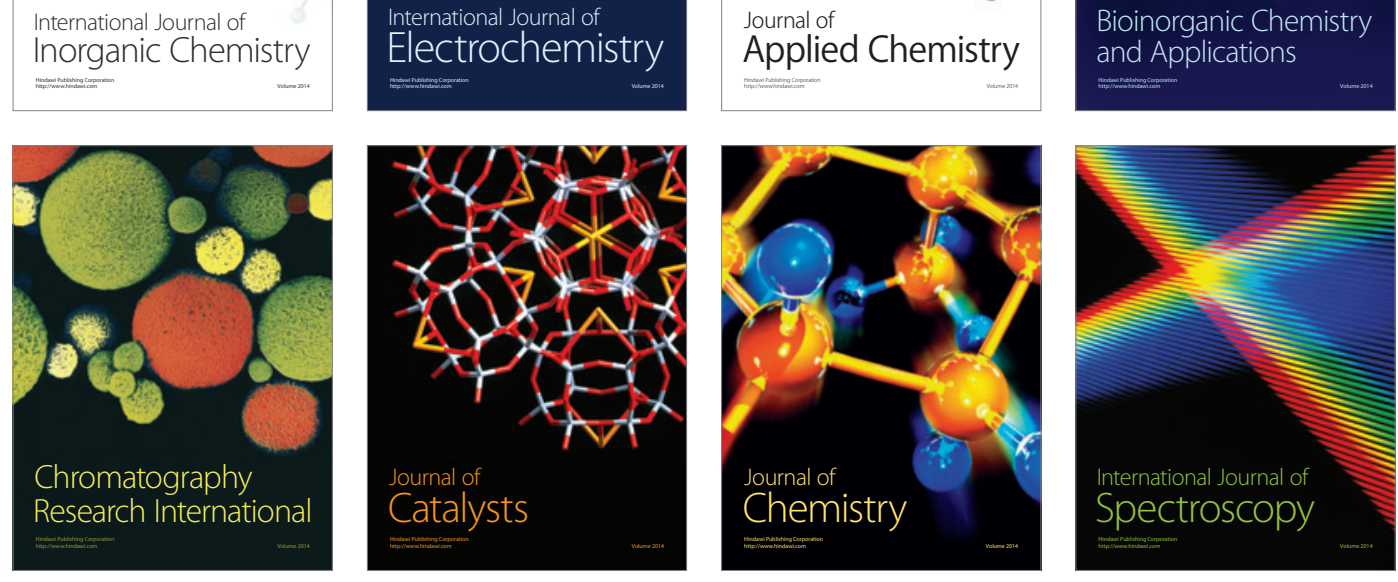